\title{
ICT Policy and perspectives of Human Development in Latin America: the Peruvian Experience
}

\author{
Edgar Ferrer'
}

\begin{abstract}
Information and Communications Technology (ICT) has been considered as an important element for economic growth and social development. However, no consensus seems to exist about the proper roles and actual effects of information technology in dynamics of socioeconomic development. Many countries around the world have seen great opportunities in implementing initiatives that would increase the ICT adoption in different areas, especially in the government. Developed countries have exploited their ICT infrastructure for implementing success projects, while developing countries are launching their own ICT based initiatives hoping to achieve a considerable impact in the society in a relatively short term. The present research is oriented to study the implications of ICT policies for enhancing the quality of life in developing countries, especially in the Latin American countries. This paper reviews some important efforts in the deployment of ICT initiative in Peru. The contribution from a research perspective is to report on some key lessons learnt and propose a set of recommendations for future implementations in similar developing nations' environments.
\end{abstract}

Keywords: E-government; human development; ICT; ICT Policy; ICT4D.

\footnotetext{
1 Turabo University. School of Business and Entrepreneurship. P.O. Box 3030 Gurabo, Costa Rica, PR 00778-3030. Telephone: 787 7437979 Ext. 4674. E-mail: edgferrer@suagm.edu 


\section{Introduction}

Information and Communications Technology (ICT) has been considered as an important element of economic growth and social development. This assertion has been supported by many researchers in the field of ICT development (Chrisanthi, 2003). In this sense, considerable empirical research effort has been centered on attributing a relationship between ICT adoption and economic growth in developing countries (Corea, 2007). However, no consensus seems to exist about the proper roles and actual effects of information technology in dynamics of socioeconomic development (Kottemann, 2009).

The adoption of ICTs has been widely spread around the world in the last two decades, especially in the so called developed world. This massive ICT adoption is driven by the achievement of competitive advantages in the private sector, but recently ICT adoption has shifted to the public sector. Many countries around the world have seen great opportunities in implementing initiatives that would increase the ICT adoption in different areas, especially in the government. The developed countries have been the first adopters of ICT policies and initiatives into their local economic development strategies, while developing countries are becoming awareness about the need to implement strategies for designing effective ICT policies. Indeed, developing countries are recognizing ICT as a potential tool for fighting against poverty and social exclusion, providing developing countries with an opportunity to meet vital development goals (UN, 2000) such as poverty reduction, basic health care, and education, far more effectively than before (Asian Development Bank, 2003).

Despite the increasing interest of governments in implementing ICT initiatives and promising to achieve socioeconomic development, the opportunities for the success of these initiatives in developing countries have been largely unexploited. Experiences in Brazil, Chile, Uruguay, and other countries show that governments in the developing world can effectively take advantage of ICT (Ndou, 2004). However, in other Latin American countries the implementation of effective ICT policies for human development could become a challenging effort.

This paper reviews some important efforts in the deployment of ICT initiative in Peru. The contribution from a research perspective is to report on some key lessons learnt and propose a set of recommendations for future implementations in similar developing nations' environments.

\section{Background}

This section supplies an initial context of understanding that supports the ideas proposed in this work.

\section{Human Development in Latin America}

Human development has been defined as "the process of enlarging people's choices. Their three essential choices are to lead a long and healthy life, to acquire knowledge and to have access to the resources needed for a decent standard of living" (OECD, 2003). The United Nations Development Programme (UNDP) has developed a means of assessing human development in a nation through the use of the Human Development Index (HDI) (UNDP, 2006). The state of human development in Latin America is documented in reports compiled and published by the UNDP (UNDP, 2009). These reports and others (World Bank, 2009) show that Latin American countries offer a complex scenery marked by poverty and inequality, deeply divided into a developed "first economy", and an underdeveloped "second economy". Those few within the "first economy" reside and work in highly developed first world enclaves with access to sophisticated ICT infrastructure. People in the "second economy", reside in depressed urban enclaves, or in rural areas afflicted by extreme and chronic poverty.

Despite history of poverty and inequality in Latin American countries, some signs of improvement in human development have been observed in recent years. According to the Human Development Report published on October 2009 by the United Nations Development Programme (UNDP, 2009) the best progress in human development in the world comes from five nations which have moved up by three or more spots in the ranking from their position in the 2008 report. These countries are China, Colombia, Peru, Venezuela, and France. Other Latin American countries have shown modest improvement while some countries seem to reveal deterioration in the human development.

The ranking of human development in Latin America is shown in Table I. The 2009 UNDP Human Development 
Report, based on data for the year 2007, assesses the quality of life of people in 182 countries in the world using such criteria as life expectancy, levels of literacy and school enrolment, Gross Domestic Product (GDP), among other economic and social indicators. From these, countries were put into four broad groupings using a Human Development Index (HDI), as follows:
Group I: Very high human development (HDI $\geq 0.900)$ Group 2: High human development $(0.800 \leq \mathrm{HDI}<0.900)$ Group 3: Medium human development $(0.50 Q \mathrm{HDI}<$ $0.800)$

Group 3: Low human development $(\mathrm{HDI}<0.500)$

\begin{tabular}{|c|c|c|c|c|}
\hline & Country & HDI value & HDI rank & Improvement \\
\hline \multirow{12}{*}{ 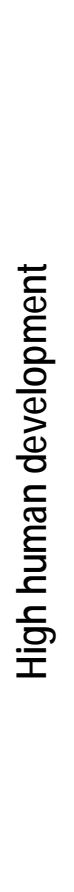 } & Chile & 0.878 & 44 & -1 \\
\hline & Argentina & 0.866 & 49 & -2 \\
\hline & Uruguay & 0.865 & 50 & -1 \\
\hline & Cuba & 0.863 & 51 & 0 \\
\hline & Mexico & 0.854 & 53 & I \\
\hline & Costa Rica & 0.854 & 54 & -1 \\
\hline & Venezuela & 0.844 & 58 & 4 \\
\hline & Panama & 0.840 & 60 & 1 \\
\hline & Brazil & 0.813 & 75 & 0 \\
\hline & Colombia & 0.807 & 77 & 5 \\
\hline & Peru & 0.806 & 78 & 5 \\
\hline & Ecuador & 0.806 & 80 & -3 \\
\hline \multirow{8}{*}{ 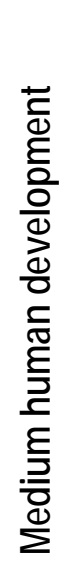 } & Dominican Republic & 0.777 & 90 & -1 \\
\hline & Paraguay & $0.76 \mathrm{I}$ & 101 & 0 \\
\hline & El Salvador & 0.747 & 106 & 0 \\
\hline & Honduras & 0.732 & 112 & 0 \\
\hline & Bolivia & 0.729 & 113 & 0 \\
\hline & Guatemala & 0.704 & 122 & 1 \\
\hline & Nicaragua & 0.699 & 124 & 0 \\
\hline & Haiti & 0.532 & 149 & 0 \\
\hline
\end{tabular}

Source: United Nations Development Programme, Human Development Report 2009

Table I: Human Development Ranking in Latin America. 


\section{Human Development in Peru}

As you can see in Table I, Peru is ranked 78st on the HDI index, placed among the lower indexes of the group 2 (high human development group). However, Peru is the second country in the world with higher improvement of HDI. In fact, in the 2009 UNDP report Peru were promoted from the Group 3 (medium development group) to the group 2 (high development group).

In terms of economy, the wealth of a country is usually is assessed by GDP (Gross Domestic Product) per capita. The performance of Peru in this field (10th out of 20) is average in comparison to other Latin American countries. However, the GDP per capita hides the level of inequality between socioeconomic groups within a country, since it presents an overall average score. To assess the level of economic inequality in a country the Gini coefficient is used (UNDP, 2009). Inequality in Peru is reflected in a high Gini coefficient of 52 . This can be read as the richest $10 \%$ of its citizens consume 30.4 times more than the poorest $10 \%$.

An important factor in assessing the human development is the health of the people. Typically, the index used for assessing health is life expectancy at birth; it reflects the ability of a population to lead a long and healthy life. It is as such heavily influenced by poverty and health pandemics such as HIVIAIDS. Some Risk factors affecting quality of health in Peru include under-nutrition, chronic diseases, and lack access to public healthcare and drugs.

Education, and its less tangible but more profound concepts of knowledge and wisdom, is a critical component of human development. Peru has succeeded well in expanding school enrolment, but some issues concerning education quality remain weak as reflected by the international literacy ranking (UNDP, 2009), where Peru is Placed 99th as result of a literacy rate of 87.9.

\section{ICT Development in Peru}

According to the World Bank (World Bank, 2007), 10.3 percent of Peruvian are accessing and using Personal Computers by 2008 , this market has a significant geographic digital divide, with the capital Lima accounting for at least 80 per cent of all PC sales. The number of Peruvian internet users reached nearly 6.9 million in 2008, representing 27.4 per cent of the population. The percentage of broadband subscribers in the general population, however, was only 2.04 per cent, while the International Internet bandwidth bits per second per capita is 2,704 .

Recent data from Peru's national statistics institute, INEI, suggests that nearly 75 per cent of Internet users use a public access point, compared with just 18.8 per cent of users who use the Internet at home, and 12.1 percent at work. Mobile telephony penetration is continuing to increase significantly, Peru will reach over 22.9 million mobile subscribers mark in June 2009 (WirelessFederation, 2009), with a mobile penetration of 79.3 lines per 100 inhabitants.

The ICT market in Peru is relatively small if it is compared with other countries in the Latin America region. Nevertheless, ICT market in Peru is projected to grow at a compound annual growth rate (CAGR) of 9.6 per cent over the 2008-2013 forecast period. This CAGR could be positively affected by the free trade agreement (FTA) between Peru and the US, which will reduce tariffs by up to 80 percent and drive IT investments. Economic growth is lifting millions of Peruvians into a middle class for whom computers are no longer beyond reach.

In October 2009, the Peruvian government confirmed that it had a budget to purchase another 152,000 Personal Computerss for schools. The purchases, from the 'One Laptop Per Child' program, are to follow the 140,000 computers purchased in 2008. Peru has upgraded its total order volume from 260,000 XO-I laptops (as reported back in December 2007) to 290,000 units. The education ministry has budgeted US $\$ 38.4$ million for the purchase of the laptops, together with accessories. Regional governments will also contribute to this project.

The E-readiness rankings 2009 published by The Economist (The Economist Intelligence Unit, 2009) ranked Peru 53th, while The Networked Readiness Index (World Economic Forum, 2009) ranked Peru 89th, but cited improvements in some institutions including those within the judicial, police and education spheres.

\section{ICT Policies in Peru}

Peru has ambitious plans in its policies towards the development of emblematic ICT based projects. The government has viewed an advanced ICT infrastructure as a way to attract foreign investment and to diversify the 
economy of the country. The country has developed a national plan for improving the ICT infrastructure, pointing to the rural area. Since 2005 the Government has sponsored the ICT Development Fund in joint with the private sector, non-governmental organizations, the civil society and other international or multinational organizations in the ICT sector. The ICT policy in Peru has been founded basically in three main objectives:

I. Establish Policies and Regulatory Framework: The Government will establish a regulatory and policy framework that facilitates the development of the country's telecommunications and ICT infrastructure and services in order to meet national, regional and international objectives.

2. Promote and Develop New Technologies: The Government will promote the use of new technologies in different sectors of the Peruvian society.

3. Develop the Country's Human Capital: The Government will facilitate the development of human capital in the telecommunications and ICT sector to meet the demands of the economy, serving both local and regional requirements.

It is not the purpose of this paper to present a rigorous analysis or review of national ICT policies in Peru. However, a number of emblematic and ICT based initiatives have been selected to be briefly presented in this paper, further analysis concerning these initiatives will be provided in subsequent sections.

\section{Digital Agenda}

The Digital Agenda initiative was launched in 2004, it was the first great initiative intended to transform and support ICT development in Peru. This initiative promised to play a central role in economic and social development in Peru. Its main goal was to enhance the Peruvian ICT emerging sector and maximize its ability to compete in local, regional, and global markets. Many ICT project related with the public sector have been deployed by means of the Digital Agenda Initiative. It has also contributed to drive major ICT based training programmes for developing the public and civil society, also called the information society.

\section{The Commission for the Development of the Information Society}

The Commission for the Development of the Information Society (CODESI) was established in June 2003 and is in charge of elaborating a Plan and activities to develop the Information Society in Peru. This Commission is composed by representatives from government, civil society, academic institutions and private sector. CODESI has created the following working boards:

Board I: Infrastructure necessary for development of Information Society.

Board 2: Development of Human Capacities.

Board 3: Development and application in social programs.

Board 4: Development of Production sectors and services.

Board 5: E-Government.

Board 6: Processes of World Summit on Information Society.

\section{FITEL - Fund of Investment in Telecommunications}

The Peruvian government manages the Fund of Investment in Telecommunications (FITEL), which gathers $1 \%$ of gross annual incomes of final and carrier service operators. FITEL is administered by OSIPTEL (The government organization principally responsible for promoting the growth of telecommunications services in Peru). Some important projects supported by FITEL include the payphone programme for rural areas and the public internet cafes programme (programa de cabinas públicas), these projects are considered the Peruvian model of access to ICTs, a viable model for universal access in developing countries.

\section{Last Mile Initiative}

The Last Mile Initiative (LMI) is a project sponsored by the United States Agency for International Development (USAID) that is being implemented in several countries worldwide. Its aim is to expand telecommunications connectivity to isolated rural areas, emphasizing the development of financially sustainable business models. In Peru, the project is being implemented by Voxiva, the local subsidiary of Voxiva International. 


\section{Digital Freedom Initiative}

The goal of the Digital Freedom Initiative worldwide is to help entrepreneurs and small businesses make better use of information and communications technology (ICT) so that they can create jobs and improve the standards of living of the families of workers. The United States, in both public and private sectors, is uniquely positioned as a world leader in the development of innovative ICTs. The strategy for Peru, as elsewhere under DFI, is therefore one that includes close partnership with the local business community as well as with Peruvian Government policy makers. This partnership will adapt ICTs to address the special problems of MSMEs (Micro, Small and Medium Enterprises) in Peru, and will seek to transform and enhance national policies and infrastructure to make these ICTs more readily accessible.

\section{E-Government Initiatives}

ONGEI (Spanish acronym for National Office of Electronic Government and Informatics) is the official organization which leads the national informatics system and other egovernments projects promoted by the national government. ONGEI is in charge of formulating egovernment strategies, ruling the informatics sector, managing information security, developing emblematical ITCs projects, giving advice to public institutions, and providing training in e-government's subjects. ONGEI has contributed in launching the official ICT based programmes. In this context, the most significant eGovernment initiatives include:

The portal of the Peruvian government:

http://www.peru.gob.pe

Citizen Services Portal:

http://www.serviciosalciudadano.gob.pe/

Economic Transparency: http://transparencia-

economica.mef.gob.pe/

The Portal for Transparency in Municipalities:

http://www.ventanapublica.org.pe/

Digital file of Peruvian Legislation:

http://www.congreso.gob.pe/ntley/default.asp

Virtual Peruvian Parliament:

http://www.congreso.gob.pe/pvp/
Employments in Peru: http://www.empleosperu.gob.pe/

\section{Findings and Discussion}

The Peruvian government in collaboration with the private sector has made important efforts for deploying ICT based initiatives in order to achieve social and economic development goals. Despite a well-intentioned ICT policy environment in Peru, several problems persist. By tracking the advances of the programmes, it is found that some progress has been achieved in their deployment, but the promised results and some goals have not been achieved.

Although indicators of human development show that Peruvians are enhancing their quality of life, Peru's performance remains poor in some ICT development indicators. For example, the rate of access and use of personal computers in Peru is low (10.3\%) if it is compared with the rate of access and use of PC in Costa Rica (23.1\%), even this rate in Peru is lower than the average in Latin America (11.3\%). In addition, this issue is largely affected by the geographic digital divide, with the capital Lima accounting for at least 80 per cent of all PC sales.

There is no clear sign that Peruvians are significantly improving quality of life as results of deploying ICT based initiatives. Similar findings have also been reported in other research studies, showing that in most country government agencies are facing capacity problems (Avgerou, 2003). This is due to complex existing process and to working culture (Heeks, 2007). Although There have been many successful ICT based initiatives in developed countries, there have been few research studies reporting positive impact of ICT initiatives on human development. Indeed, there no exists a clear evidence to prove that ICT is an enabler for socioeconomic development in developing countries.

\section{Lesson Learnt}

This paper is focused on determine the practices in ICT policy that might be causing slow transformation in Peru. The lessons learnt by this assessment could be used in benefit of developing countries, especially the Latin American countries. The author has identified some significant issues affecting the success of ICT policies for human development. 
Overoptimistic Goals: Unfortunately, most ICT initiatives in Peru have failed to meet their goals due to highly optimistic initiatives motivated by successes achieved in developed countries, without realizing the time and effort required to fit such initiatives in a complex bureaucratic structure and a particular culture of the public sector. For example, the portal of the Peruvian government promised ambitious attributes such as capabilities for electronic tax payment systems, but these resources have become easier said than done, given that the bureaucratic processes involved in the Peruvian tax payment system have turned into an obstacle.

The promise of deploying one portal offering government services online in each municipality (Esteves \& Bohórquez, 2007) seems to be unreachable today, when most municipal portals are limited to deliver official forms to be downloaded, and information about the municipality displayed in static web pages.

Planning effective ICT based projects founded on realistic goals might become a challenging work; especially in the developing world. This issue was observed by Heeks \& Bailur (2007), who were surprised to find that optimistic approaches are dominant in most studies. Heeks (2006) had previously indicates that in developing countries, 35\% of Information System projects ended with failures, 50\% ended with partial failures and only 15\% have succeeded.

Short term planning: In 2002, the Informatics' Development Plan (Instituto Nacional de Estadística e Informática del Perú, 2002) stated as central objective to modernize public administration and to promote decentralization in the Peruvian government by using ICT intensively. This central objective would be achieved by deploying the ICT National Infrastructure between 2002 and 2006. Unfortunately, this plan failed to achieve its goals as result of short time planning.

Delivering positive results to users in a relatively short term is a desired goal when planning ICT based projects. However, some ICT initiatives have failed due to short time planning. Most ICT initiatives in Peru have been scheduled to achieve substantial results within short timeframes. Agenda Digital Peru (Agenda Digital Peruana, 2009) has pretended to create an ICT based society in five years while the e-Government initiative had the vision of delivering a plethora of government services online for any citizen within five years of its implementation.
People responsible for implementing ICT initiatives in Peru have been tempted to rush in obtaining large results in short time. Obtaining large results in short time has been marked by the fact that government agencies across Peru were only given limited time frames to comprehend the rapid changes emerged by the application of ICT technologies, and the fact that the goals of ICT transformation were not judiciously partitioned into well defined separate stages.

The National ICT Plan: Peru is maturing a national ICT plan to stimulate private sector participation, increase ICT investments, support the local and international commerce, and create job opportunities. The fundamental idea is to meet the objective of preparing the next generations to deal with ICT. The national ICT plan would represent the nation's strategic plan for the future with ICT as an enabler of human development. Some ICTs initiatives are running in Peru while the Peruvian ICT national plan is not yet consolidated. The national ICT plan would reflects a clear understanding that ICT plays a major role in empowering economic and social development, and in supporting decision makers who are addressing economic and social reforms (Hashem, 2002).

Despite a well-intentioned ICT policy environment in Peru, most of the initiatives have not been conceived in a frame of a global ICT policy plan. The main ICT project have clearly established its mission, vision, and objectives into an strategic plan, however there no exists details about a broad, overall view or perspective of the project in a national context. Peru does not have a long term plan rigorously designed, in which all the ICT initiatives are developed. Instead, people responsible for implementing ICT initiatives in Peru have deployed various ICT based initiatives in hoping to achieve a considerable impact in the Peruvian society in a relatively short term. The Informatics' Development Plan (Instituto Nacional de Estadística e Informática del Perú, 2002) and Agenda Digital Peru (Agenda Digital Peruana, 2009) could be considered as the great master plan surrounding all ICT based initiatives in Peru, but these plans were formulated impulsively, they only have short term goals which were to be achieved within five years.

A well defined national ICT plan enables appropriate environment for developing effectives ICT policies, creating in this way an "e-Atmosphere" for eliminating 
some habitual obstacles that have affected implementation of ICT policies in developed countries. Such obstacles are related with complicated bureaucratic structures, pertinent reforms to the current juridical structure, and other legal issues.

People-centered planning: Developers of ICT policies in Peru have be concerned about a wide participation of persons from different sectors, always considering stakeholder as a fundamental element in any successful project. Some ICT based initiatives in Peru have been conducted through joint collaborative efforts between the government, the private sector, non-governmental organizations, the civil society and other international or multinational organizations in the ICT sector. This synergetic interaction in the ICT policy is fundamental for diffusing ICT awareness among different segments of the community.

A fundamental aspect in the success of ICT policies for enabling human development is to determine the real needs of people. Some research studies (Welch, 2005) have highlighted the problem of countries not understanding their people needs from major ICT projects such as e-Government. They point to this issue as being an important factor causing countries worldwide not implementing responsive ICT strategies. Others have called for investigating this practice, especially in the developing world where the problem is expected to be even bigger than the developed world (Centeno, 2005).

An assessment has been made (Quiroz \& Suarez, 2007) in order to recognize how people are assimilating some egovernment initiatives in Peru. The study reveals disappointing results concerning responsive use of the basic e-government services. See for example the following results:

Only $31.9 \%$ of Internet users have said to knows the portal of the Peruvian government.

Only 53.9 of users familiar with the portal have used the portal in the last three months.

Only $16.0 \%$ of people using the portal have made an electronic transaction.

Only $19.0 \%$ of people using the portal have considered the service is good or very good.
Only $14.90 \%$ of people using the portal have said to know the Citizen Services Portal.

Apparently the emblematic project of e-Governmet in Peru is not well appreciated by people. Clearly most people still do not know about the existence of an eGovernment portal. This kind of result is common in eGovernment initiatives in the developing world, usually it is attributed to issues involved in e-readiness and eparticipation. However, most e-Government projects in developing countries start designing strategies without a simple assessment to determine what level and type of services people require from such ICT initiatives.

\section{Concluding Remarks}

Peru like other Latin American countries is facing important economic challenges. ICTs present a means of addressing some of these problems. ICT policies centered in human development could be a powerful tool for the introduction effective ICT products and services in benefit of most underprivileged people. Although there no exists a clear evidence to prove that ICT is an enabler for socioeconomic development in developing countries, it could be used as a means for implementing solutions that could tackle critical problems. For example, e-health and elearning systems have been used in the developing world for mitigating critical problems in health and education.

In the developed world, ICT have significantly contributed to improve quality of public services, and commercial activities. The ICT initiatives in the developed world have fitted with advanced ICT infrastructure, more organized government, and even their culture. Driven by positive results in the developed world, developing countries such as Peru established their ICT policies and started emblematic projects hoping to achieve social and economic development. However, deploying successful ICT projects in developing world have become a challenging work, requiring significant effort and resources. The development of the systems and infrastructure necessary to deploy ICT based initiatives requires a judicious revision of the government, and especially the social and cultural frameworks of the country.

The lesson learned from the Peruvian experience is projectable to other developing countries, especially the Latin American countries; most of them have common characteristics in existing infrastructure, governmental 
structures, process, and culture. In order to achieve better results in ICT initiatives, developing countries have to should adopt realistic long-term plans. The strategy should accommodated the country's ICT initiatives and reflect acceptable levels of change adjusted to the country's resources, and executed in stages within reasonable timeframes that would respond to both the social and cultural changes brought by ICT. Developing countries implementing ICT initiatives should consider suitable strategies in order to empower their citizens before going to advanced stages of the initiatives.

Future work includes a more exhaustive study about ICT policies for human development in Latin America, identifying successful ICT initiatives, and how they can be related with the human development in the country.

\section{References}

AGENDA DIGITAL PERUANA (2009), http://www.codesi.gob.pe/codesi/ Agenda Digital Peruana, 2009.

ASIAN DEVELOPMENT BANK (ADB) (2003). Toward EDevelopment in Asia and the Pacific: A Strategic Approach for Information and Communication Technology, http://www.adb.org/Documents/Policies/ICT [Accessed 12 September 2009].

CHRISANTHI A. (2003) The link between ICT and economic growth in the discourse of development. In: Korpela, Mikko and Montealegre, Ramiro and Poulymenakou, Angeliki, (eds.) Organizational information systems in the context of globalization. Springer, New York, USA, PP. 373-386.

CENTENO, C., Van-Bavel, R., Burgelman, J.C. (2005), A Prospective View of e-Government in the European Union, The Electronic Journal of e-Government, Volume 3, Issue 2, pp.59-66, 2005.

COREA, S. (2007) Promoting Development through Information Technology Innovation: The IT Artifact, Artfulness, and Articulation, Information Technology for Development, Volume I3, Issue I, Pp. 49-69, 2007.

ECONOMIST INTELLIGENCE UNIT (The) (2009), Ereadiness rankings 2009: The usage imperative. The Economist. A report from the Economist Intelligence Unit written in cooperation with the IBM Institute for Business Value, 2009.

ESTEVES, J., Bohórquez, V. (2007). Analyzing the development of municipal e-Government in Peruvian cities. In Proceedings of the 9th International Conference on Social Implications of Computers in Developing Countries, São Paulo, Brazil, May 2007.

Instituto Nacional de Estadística e Informática (2002) "Estrategia para la construcción de la infraestructura nacional de información, 2002". Instituto Nacional de Estadística e Informática del Perú, 2002, http://www.ongei.gob.pe/estudios/publica/estudios/Lib5160/ Libro.pdf . [Accessed 05 October 2009]-

HASHEM, S. (2002), Bridging the Digital Divide in Egypt: Facing the Challenges, Proceedings of the UNCTAD ECommerce First Expert Meeting, 10-12 July, 2007.

HEEKS, R. (2006) Theorizing ICT4D research, Information Technologies and International Development, Volume 3, Issue 3, pp. I-4, 2006.

HEEKS, R., Bailur S., (2007), Analyzing e-Government Research: Perspectives, Philosophies, Theories, Methods, and Practice, Government Information Quarterly, Volume 24, Issue 2, pp. 243-26, April 2007.

KOTTEMANN J. E. (2009) The effects of technological, institutional and fiscal readiness on the extent of nations' e-government, Electronic Government, Volume 6, Issue 3, pp. 327-34I, 2009.

NDOU, V. (2004), e-Government for Developing Countries: Opportunities and Challenges, The Electronic Journal of Information Systems in Developing Countries, Volume 18, Number I pp. I-24, 2004.

OECD (2003). OECD glossary of statistical terms. http://stats.oecd.org/glossary/detail.asp?!D= 1265 [Accessed OI May 2008].

QUIROZ E., Suarez J. (2007), "Diagnostico sobre la percepción del ciudadano en cuanto al uso del Portal del Estado Peruano y el Portal de Servicios al Ciudadano", Presidencia del Consejo de Ministros, República del Perú, http://www.ongei.gob.pe/estudios/publica/estudios/percepci on_ongei_2007.pdf [Accessed October 8, 2009]. 
UN (2000), United Nations Millennium Development Goals. Website, http://www.un.org/millenniumgoals/ bkgd.shtml [Acessed I6 June 2009].

UNDP (2006), UNDP: United Nations Development Programme (2004 to 2006). Human development report 2006. UNDP, http://hdr.undp.org/en/reports/ [Accessed 30 September 2009].

UNDP (2009), Human Development Report 2009. Overcoming barriers: Human mobility and development", UNDP: United Nations Development Programme, http://hdr.undp.org/en/ [Accessed 08 October 2009].

WELCH E.W., Hinnant, C.C., Moon J.M. Linking Citizens Satisfaction with E-Government and Trust in Government, Journal of Public Administration Research an Theory, Volume 15, Number 3, pp.37I-39I, 2005.

WIRELESSFEDERATION (2009) Peru mobile penetration stands at $75.8 \%$, http://wirelessfederation.com/news//5982peru-mobile-penetration-stands-at-75.8 [Accessed 06 October 2009].

WORLD ECONOMIC FORUM (2009) The Networked Readiness Index 2008-2009 rankings, The Global Information Technology Report 2008-2009: Mobility in a Networked World", 2009 World Economic Forum.

WORLD BANK (2009), World Development Indicators 2009, The World Bank, 2009.

\section{About the author}

Edgar Ferrer is assistant professor at Turabo University, Puerto Rico. He received a BSc. in Computer Science from Universidad del Zulia, Venezuela, MSc. degree in Computer Science from the Universidad de los Andes, Venezuela in 2003, and the Ph.D. degree in Computing and Information Sciences and Engineering from the University of Puerto Rico at Mayaguez in 2008. His current research interests include algorithms and architectures for computations in finite fields, computational biology, artificial Intelligence, decision support systems, and IT policy. 